\title{
Supercritical Extraction Process of Allspice Essential Oil
}

\author{
Yasvet Y. Andrade-Avila, ${ }^{1}$ Julian Cruz-Olivares, ${ }^{1,2}$ César Pérez-Alonso, ${ }^{1}$ \\ Ciro Humberto Ortiz-Estrada, ${ }^{3}$ and María del Carmen Chaparro-Mercado ${ }^{4}$ \\ ${ }^{1}$ Facultad de Química, Universidad Autónoma del Estado de México, Paseo Colón Intersección Paseo Tollocan S/N, \\ 50120 Toluca, MEX, Mexico \\ ${ }^{2}$ MCCM Ciencia E Innovación Tecnológica S.A. de C.V., Av. Benito Juárez Sur 1002, Col. Universidad, 50130 Toluca, MEX, Mexico \\ ${ }^{3}$ Secretaría de Gobernación, CNS-Policía Federal, Sistema de Desarrollo Policial, Poniente 116-590, Edificio A, Tercer Piso, \\ Col. Industrial Vallejo, Deleg. Azcapotzalco, 02300 Ciudad de México, Mexico \\ ${ }^{4}$ Departamento de Ingeniería y Ciencias Químicas, Universidad Iberoamericana, Prol. Paseo de la Reforma 880, Lomas de Santa Fe, \\ Álvaro Obregón, 01219 Ciudad de México, Mexico
}

Correspondence should be addressed to Julian Cruz-Olivares; jcruzo@uaemex.mx

Received 18 May 2017; Accepted 27 June 2017; Published 11 October 2017

Academic Editor: Mostafa Khajeh

Copyright (C) 2017 Yasvet Y. Andrade-Avila et al. This is an open access article distributed under the Creative Commons Attribution License, which permits unrestricted use, distribution, and reproduction in any medium, provided the original work is properly cited.

\begin{abstract}
Allspice essential oil was extracted with supercritical carbon dioxide $\left(\mathrm{SC}-\mathrm{CO}_{2}\right)$ in a static process at three different temperatures $(308.15,313.15$, and $318.15 \mathrm{~K})$ and four levels of pressure $(100,200,300$, and 360 bar). The amount of oil extracted was measured at intervals of $1,2,3,4,5$, and $6 \mathrm{~h}$; the most extraction yield reached was of $68.47 \%$ at $318.15 \mathrm{~K}, 360 \mathrm{bar}$, and $6 \mathrm{~h}$ of contact time. In this supercritical extraction process, the distribution coefficient $\left(K_{D}\right)$, the mean effective diffusion coefficient $\left(D_{\text {ef }}\right)$, the energy of activation $\left(E_{a}\right)$, the thermodynamic properties $\left(\Delta G^{0}, \Delta H^{0}\right.$, and $\left.\Delta S^{0}\right)$, and the apparent solubility $(S)$ expressed as mass fraction $(\mathrm{w} / \mathrm{w})$ were evaluated for the first time. At the equilibrium the experimental apparent solubility data were successfully correlated with the modified Chrastil equation.
\end{abstract}

\section{Introduction}

Allspice, Pimenta dioica L. Merrill, or Pimenta officinalis belongs to the family Myrtaceae and is known in English as allspice or pimento, in French as piment jamaique or touteepice, in Portuguese as pimenta da Jamaica, and in Spanish as pimienta gorda [1]. Traditionally the dried mature but not ripe berries are consumed as spice and commonly used for flavoring food, but the essential oil of this fruit and the aqueous extracts of leaves of the pimento tree have been used as carminative, hypoglycemic, stimulant, antimicrobial, acaricide, and antifungal pharmaceutical preparations [2-8]. Moreover, since mankind has chosen to consume natural products the allspice essential oil is used massively in food, pharmaceutical, and perfume industries [9]. Due to its high content of eugenol, methyl eugenol, myrcene, and caryophyllene $[7,10]$ The high levels of eugenol contained in clove essential oil give it strong biological activity and antimicrobial activity. This phenolic compound can denature proteins and reacts with cell membrane phospholipids changing their permeability [11]. This essential oil has been studied for different applications. The antioxidant potential of allspice oil was evaluated by many researchers and all of them have found that this essential oil has good antioxidant activity and can be utilized as a natural antioxidant $[7,8,12,13]$. In more specific applications the allspice essential oil was used as an anti-inflammatory $[14,15]$. Also extraordinary applications of the leaves and berries extracts of allspice have been reported in the fields of medicine and materials science $[16,17]$.

Based on these studies, it is important to develop new and clean processes for extracting essential oils from solid matter. Traditionally, allspice essential oil was extracted by hydrodistillation, steam distillation, or solvent extraction. Recently, in concordance with green chemistry, supercritical fluid extraction has increased the attention as an important alternative to conventional methods. Supercritical fluids have adjustable extraction characteristics due to their density, 
which can be controlled by changes in temperature and pressure [18].

Carbon dioxide is commonly used as a supercritical fluid because of its nontoxicity, nonflammability, low cost, moderate critical pressure, high critical density, and low critical temperature. The low value of critical temperature is the most attractive property to extract thermolabile compounds [19]. The allspice essential oil extracted with supercritical $\mathrm{CO}_{2}$ has superior quality and has better flavor, compared with the oil obtained through steam distillation [20].

Several advantages offer the technology of supercritical fluids in the processes of extracting essential oil from vegetable matter with $\mathrm{SC}-\mathrm{CO}_{2}$, but in many of these solid-fluid systems, it is not well defined as the kind of phenomenon that controls the extraction process. The extraction of essential oil from a solid matter could be controlled by diffusion or kinetics phenomena but the thermodynamic properties could indicate if the process is possible to develop. Depending on the extraction conditions and the solid sample matrix, either the rate of initial extraction step or the elution step can control the extraction rates. In the systems where the solubility is sufficient for the extraction feasible, the solubility of the solute in the supercritical fluid greatly affects the rate of extraction, due to its effect on the distribution coefficient [21, 22]; in other cases, the rate of extraction is limited by many transfer mass mechanisms; among these is the internal diffusion of the solute into the interstices of the solid matter; this mechanism is related to the effective diffusion coefficient.

The solubility is one of the most important thermophysical parameters considered in the application of the supercritical fluid technology in the supercritical extraction processes using $\mathrm{CO}_{2}$ [23]. Generally, the solubility depends on the temperature and pressure of the system, besides the chemistry nature of the solute, as well as the physicochemical properties such as molecular weight, polarity, and solute vapor pressure, which are related to the intermolecular interactions [24, 25].

The estimation of transport parameters like the diffusion, the distribution coefficients, and the physicochemical properties like apparent solubility, the activation energy, and the thermodynamic properties could facilitate the design of extraction process at pilot plant.

The aim of this work was to study the effects of pressure and temperature on the apparent solubility of allspice essential oil in $\mathrm{SC}-\mathrm{CO}_{2}$, correlate the experimental apparent solubility data with the modified Chrastil equation, and determine the distribution coefficient, the mean effective diffusion coefficient, the energy of activation, and the thermodynamic properties of the supercritical extraction process.

\section{Materials and Methods}

2.1. Sample Preparation. Allspice berries were bought previously dried in a laboratory fluidized bed dryer [26] at $343.15 \mathrm{~K}$ of inlet air temperature to "El Pimiento" ranch, located at La Mesa, Puebla, Mexico. The dried berries were ground using a conventional electric mill and sieved with mesh number 20, giving an average size of particles of $8.5 \cdot 10^{-4} \mathrm{~m}$.
Carbon dioxide (99.99\% purity) was purchased from INFRA (México).

2.2. Static Extraction Process. The high-pressure extraction cell was loaded with $100 \mathrm{~g}$ of dried and milled allspice. The cell was connected to the apparatus tubing lines and immersed in a water bath, equipped with a temperature controller which controls the operational temperature within $(0.1 \mathrm{~K}) . \mathrm{A} \mathrm{CO}_{2}$ stream was passed through the lines in order to displace the air in the pipe and in the extraction cell. Carbon dioxide was compressed using a high-pressure liquid pump (LabAlliance A19284). When the water bath reaches the experiment temperature, the cell is pressurized with $\mathrm{CO}_{2}$ until the desired experimental pressure is attained. Pressure was measured with a high-pressure transducer (Sensotec THE/7093-03). After the pressure and the temperature are stable, the magnetic stirring plate positioned under the extraction cell is switched on, and the heterogeneous mixture of milled allspice with $\mathrm{CO}_{2}$ is left to stir for a determined time. After reaching the specified contact time, the supercritical $\mathrm{CO}_{2}$ with dissolved essential oil passes through a heated micrometer valve and is subsequently discharged in a refrigerated recovery cell $(273.15 \mathrm{~K})$ where the extracted oil is collected. The outflow rate was carefully controlled by micrometer valve because the abrupt expansion of the mixture causes cooling and frost formation obstructing the exit. A calibrated wet gas meter (Precision Wet Test Meter, Model 63126) was used to measure the total amount of $\mathrm{CO}_{2}$. The amount of allspice oil collected in the recovery cell was determined by gravimetric measurements performed on an analytical balance with an uncertainty of $\pm 0.001 \mathrm{~g}$. The complete extracted oil accumulated in the outlet tubes was recovered by ethanol solvent. The procedure was repeated in duplicate and the identical operation conditions.

A schematic representation of the experimental apparatus constructed in stainless steel is shown in Figure 1.

2.3. Solubility. The apparent solubility expressed as mass fraction $(\mathrm{w} / \mathrm{w})$ was determined in intervals of $1 \mathrm{~h}$ for each temperature and pressure. The results of the experimental apparent solubility were correlated with modified Chrastil model $[27,28]$. This model is based on the density of the pure supercritical $\mathrm{CO}_{2}$ and is widely used for the correlation of solid-supercritical fluid equilibrium, mainly due to its simplicity and easy application.

The modified Chrastil model is expressed as follows:

$$
\ln S=\left(k_{0}+k_{1} \cdot d\right) \ln d+\frac{\left(a_{0}+a_{1} \cdot d\right)}{T}+b
$$

where $S$ is the solubility expressed as mass fraction (w/w), $T$ is the temperature in $\mathrm{K}$, the association numbers $k_{0}$ and $k_{1}$ are the average number of solvent molecules in the solvated complex, $a_{0}$ and $a_{1}$ depend on the heat of solvation and vaporization of solute, and $b$ is a function of $k$ and depends 


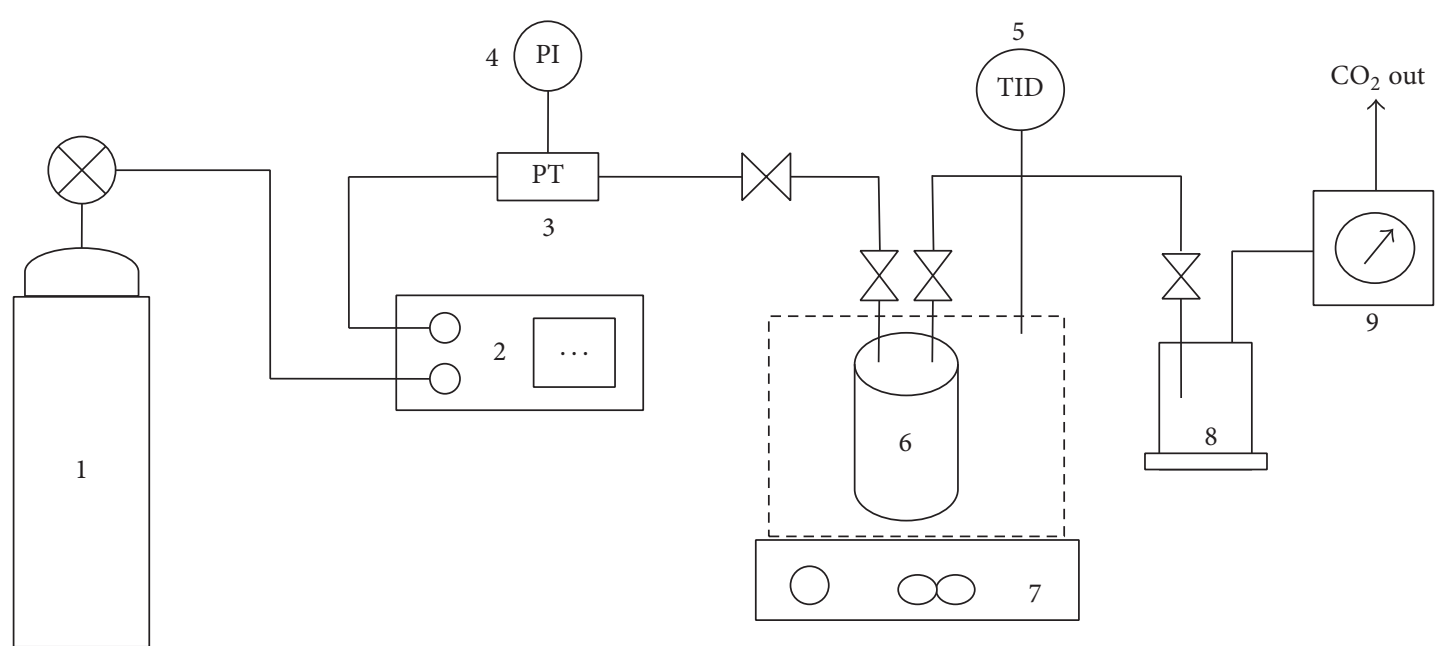

FiguRE 1: Schematic diagram of experimental setup. 1, carbon dioxide cylinder; 2, high-pressure pump; 3, pressure transducer; 4, pressure indicator; 5, temperature indicator driver; 6 , high-pressure extraction cell; 7, magnetic stir device; 8 , oil recovery cell; 9 , wet gas meter.

also on molecular weight of the solute and the supercritical fluid, and $k$ also depends on the supercritical fluid density $(d)$ :

$$
\begin{aligned}
& k=k_{0}+k_{1} \cdot d, \\
& a=a_{0}+a_{1} \cdot d .
\end{aligned}
$$

2.4. Distribution Coefficient. In a solid-fluid extraction system, the distribution coefficient $\left(K_{D}\right)$ is expressed by

$$
K_{D}=\frac{m_{\mathrm{oe}}}{m_{\mathrm{or}}},
$$

where $m_{\mathrm{oe}}$ is the mass of essential oil in the SC- $\mathrm{CO}_{2}$ and $m_{\mathrm{or}}$ is the mass of essential oil remainder into the milled allspice. This model assumes that the kinetics of the initial extraction step and subsequent fluid-solid partitioning are rapid and thus do not significantly affect the extraction rate. If the size of the solid particles is uniform and does not change, the mass of the oil in each unit mass of extraction fluid that remains into the milled allspice for a particular period can be calculated based on the $K_{D}$ values.

In order to obtain $m_{\mathrm{or}}$, firstly it was necessary to calculate the maximum amount of essential oil in the milled allspice (3.815\%) in dry basis, according to the standardized method of the Mexican Norm (NMX-FF-063-1987).

2.5. Effective Diffusion Coefficient and Energy of Activation. To estimate the effective diffusion coefficient $\left(D_{\text {ef }}\right)$ at different temperatures, the equation obtained from the approximate analytical solution of Fick's second law is used [26, 29]. Ground allspice particles were considered as spherical particles of constant diameter. The resulting expression of Fick's second law for this particular case is represented by

$$
\frac{q}{q_{0}}=\frac{6}{\pi^{2}} \sum_{n=1}^{\infty} \frac{1}{n^{2}} \exp \left[-n^{2} \pi^{2} D_{\mathrm{ef}} \frac{t}{r^{2}}\right]
$$

where $q$ is the concentration of remaining oil in the solid particle, $q_{0}$ is the initial concentration of oil, $r$ is the particle radius of the solid sample, and $t$ is the time of extraction.

To calculate the activation energy $\left(E_{a}\right)$ for the diffusion process, firstly it is necessary to calculate the mean effective diffusion coefficient $\left(\overline{D_{\text {ef }}}\right)$ utilizing (5) and the experimental data of isothermal extraction curves

$$
\overline{D_{\mathrm{ef}}}=\frac{\int_{q_{0}}^{q} D_{\mathrm{ef}}(q) d q}{\int_{q_{0}}^{q} d q} .
$$

The $E_{a}$ is a temperature dependent parameter and follows an Arrhenius relationship as is shown in

$$
\ln \overline{D_{\text {ef }}}=\ln D_{0}-\frac{E_{a}}{R}\left(\frac{1}{T}\right) .
$$

Using (6), a plot of $\ln D_{\mathrm{ef}}$ versus $1 / T$ yields a straight line with slope $-E_{a} / R$, where $D_{0}$ is the Arrhenius factor, $R$ is the gas constant $(8.314 \mathrm{~J} / \mathrm{mol} \mathrm{K})$, and $T$ is the absolute temperature in $\mathrm{K}$.

2.6. Thermodynamic Properties. The thermodynamic parameters of the extraction process could determine the feasibility of the process. Negative values of the free energy $\left(\Delta G^{0}\right)$ indicate that the process is spontaneous, endothermic, or exothermic which is determined depending on the value of the enthalpy $\left(\Delta H^{0}\right)$ and the reversibility of the process could be described by the value of entropy $\left(\Delta S^{0}\right)$.

The thermodynamic parameters were evaluated from the following equation:

$$
\Delta G^{0}=-R T \ln K_{D}
$$

where $K_{D}$ is the distribution coefficient, $\Delta G^{0}\left(\mathrm{~J} \mathrm{~mol}^{-1}\right)$ is the free energy of extraction, $T(\mathrm{~K})$ is the absolute temperature, and $R$ is the universal gas constant. 


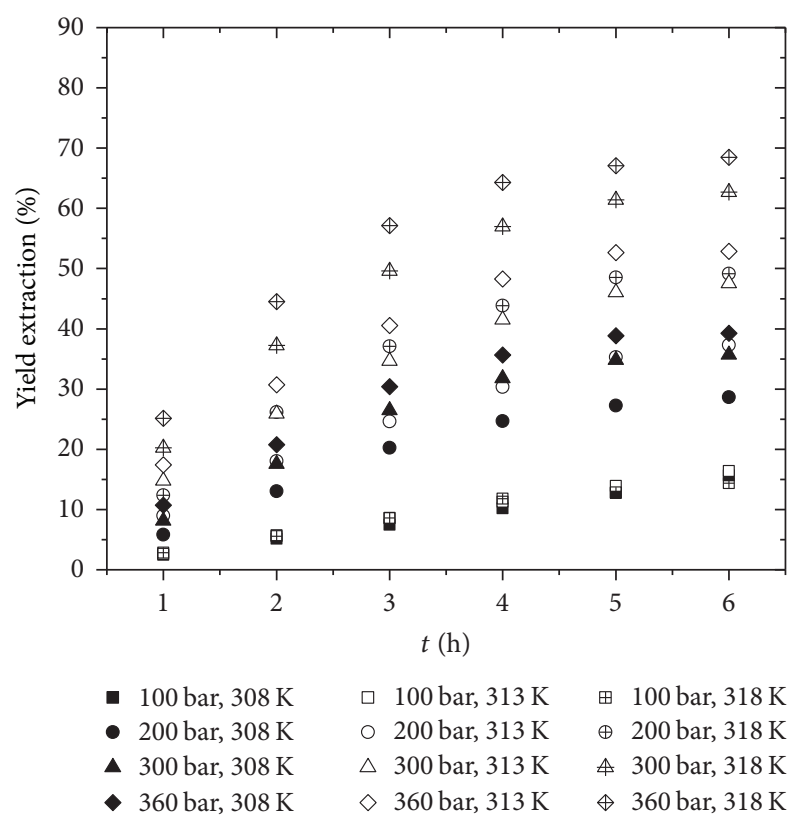

Figure 2: Extraction yield (\%) of allspice essential oil at different contact times, temperatures, and pressures.

$K_{D}$ may be expressed in terms of the $\Delta H^{0}\left(\mathrm{~J} \mathrm{~mol}^{-1}\right)$ and $\Delta S^{0}\left(\mathrm{~J} \mathrm{~mol}^{-1} \mathrm{~K}^{-1}\right)$ as a function of the temperature:

$$
\ln K_{D}=\frac{\Delta H^{0}}{R}\left(\frac{1}{T}\right)+\frac{\Delta S^{0}}{R}
$$

and the values of $\Delta H^{0}$ and $\Delta S^{0}$ can be calculated from the slope and intercept of the $\ln K_{D}$ versus $1 / T$ plot.

2.7. Characterization of Essential Oil. The concentration of various major components of the essential oil was determined by the gas chromatography method coupled to a mass spectrometer (GC-MS). It was performed by an HP Agilent $190915 / 433 \mathrm{E}$ team with an HP-5MS column $(30 \mathrm{~m} \times 0.25 \mathrm{~mm}$ i.d. $0.25 \mu \mathrm{m})$. Helium is used as the carrier gas with a constant flow of $1 \mathrm{ml} \cdot \mathrm{min}^{-1}$. The division ratio will be $100: 1$, and the sample volume injected will be $1.0 \mu \mathrm{l}$. For different temperature ranges the heating ramps were $20 \mathrm{~K} \cdot \mathrm{min}^{-1}$ for $343.15-503.15 \mathrm{~K}$ (retention time of $10 \mathrm{~min}$ ), also $20 \mathrm{~K} \cdot \mathrm{min}^{-1}$ at $503.15 \mathrm{~K}$ (retention time of $2 \mathrm{~min}$ ), and then $8 \mathrm{~K} \cdot \mathrm{min}^{-1}$ at $553.15 \mathrm{~K}$ (retention time of $5 \mathrm{~min}$ ). The temperatures of the injector, the transfer line, and the ionization source are 513.15, 523.15, and 503.15 K, respectively. Electron ionization energy was $70 \mathrm{eV}$. Mass spectra were recorded within 20 to $250 \mathrm{GC}-$ MS. The components of the oil were identified by comparison of their mass spectra with those of the system database.

\section{Results and Discussion}

3.1. Temperature and Pressure Effect on the Yield Extraction. The pressure and the temperature affected significantly the extraction yield of allspice essential oil (Figure 2). Pressure and temperature modify the apparent solubility of allspice oil in the SC- $\mathrm{CO}_{2}$ (Table 1). Increasing the pressure at constant temperature will increase the density and the solvent power of $\mathrm{SC}-\mathrm{CO}_{2}$. The effect of temperature upon the extraction could be explained in two ways. Increasing temperature under a constant pressure, on one hand, increases the solute's volatility and diffusion, which helps the extraction of the solute; on the other hand, it decreases the density and consequently the solubility capacity of supercritical $\mathrm{CO}_{2}$ [30]. In this case only at the first hour the extraction yield decreases when temperature increases (Figure 2). This means that at higher contact time the equilibrium was reached; also the effect pressure increases the solvent power of $\mathrm{SC}-\mathrm{CO}_{2}$, minimizing the temperature effect. Similar results were found in the oil extraction process rosehip seed and parsley seed with $\mathrm{SC}-\mathrm{CO}_{2}[22,31,32]$.

As shown in Figure 2 the percentage of oil extracted increased with the time. This result shows that extraction process of allspice essential oil requires long extraction times to obtain more than $60 \%$ of yield. This agrees with other studies where essential oil from savory was extracted with supercritical $\mathrm{CO}_{2}$ [21]. According to the results presented in Figure 2, it is possible to say that only at the highest pressures and temperatures is the equilibrium reached and is the process favorable.

3.2. Solubility Calculation and Correlation. It is important to note that although the percentage of allspice oil extraction increased with increasing temperature and pressure, the effect of temperature on the apparent solubility of allspice oil is not as prominent as the effect of pressure due to an increase in temperature; this causes an increase in solute vapor pressure but decreases the density of supercritical carbon dioxide [33].

The apparent solubility of allspice essential oil was determined at $308.15,313.15$, and $318.15 \mathrm{~K}$, in the pressure range of $100,200,300$, and 360 bar. Table 1 shows the experimental and calculated apparent solubility of allspice essential oil in $\mathrm{SC}-\mathrm{CO}_{2}$, as a function of the temperature and the pressure at $6 \mathrm{~h}$ of contact time when the equilibrium was reached. By comparing the $S^{\text {exp }}$ and $S^{\text {cal }}$ the average absolute relative deviations (AARDs) were less than $1.0 \%$.

The apparent solubility data of allspice essential oil were correlated with (1), and the correlation results are plotted in Figure 3. The optimal fitting parameters are presented in (9) which correlates adequately with $\left(r^{2}=0.9996\right.$, rmsd $=$ 0.0018 ) the experimental apparent solubility values, at $6 \mathrm{~h}$ of contact time when the equilibrium was reached

$$
\begin{aligned}
\ln S= & \left(-1.47-1.88 \cdot 10^{-3} d\right) \ln d \\
& +\frac{\left(5.46 d-1.17 \cdot 10^{4}\right)}{T}+30.29 .
\end{aligned}
$$

3.3. Distribution Coefficient, $K_{D}$. The $K_{D}$ values determined at different values of pressure and constant temperature are reported in Figure 4 . The $K_{D}$ values decreased with an increase in pressure, which indicates that the concentration of allspice essential oil in the supercritical $\mathrm{CO}_{2}$ at equilibrium 
TABLE 1: Apparent solubility ${ }^{\mathrm{a}}$ of allspice essential oil in $\mathrm{SC}-\mathrm{CO}_{2}$ at equilibrium time of $6 \mathrm{~h}$.

\begin{tabular}{|c|c|c|c|c|}
\hline$T(\mathrm{~K})$ & $P$ (bar) & $10^{6} S^{\exp }(\mathrm{w} / \mathrm{w})$ & $10^{6} \mathrm{~S}^{\mathrm{cal}}(\mathrm{w} / \mathrm{w})$ & AARD (\%) \\
\hline \multirow{4}{*}{308.15} & 100 & 1.395 & 1.385 & \multirow{4}{*}{0.51} \\
\hline & 200 & 1.724 & 1.719 & \\
\hline & 300 & 1.867 & 1.877 & \\
\hline & 360 & 1.939 & 1.948 & \\
\hline \multirow{4}{*}{313.15} & 100 & 1.873 & 1.893 & \multirow{4}{*}{0.68} \\
\hline & 200 & 2.389 & 2.395 & \\
\hline & 300 & 2.594 & 2.589 & \\
\hline & 360 & 2.707 & 2.674 & \\
\hline \multirow{4}{*}{318.15} & 100 & 2.612 & 2.605 & \multirow{4}{*}{0.38} \\
\hline & 200 & 3.360 & 3.345 & \\
\hline & 300 & 3.571 & 3.571 & \\
\hline & 360 & 3.639 & 3.666 & \\
\hline
\end{tabular}

${ }^{a}$ Solubility is expressed as mass fraction $(\mathrm{w} / \mathrm{w})$.

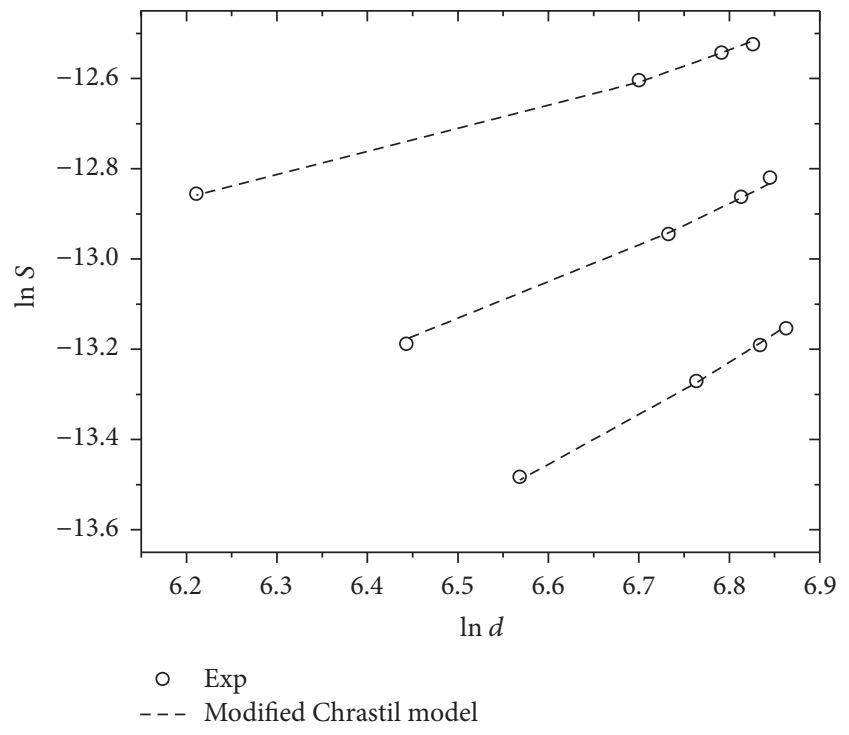

FIGURE 3: Validation of the modified Chrastil model for allspice essential oil in the pressure range of (100 to 360) bar at different temperatures. Symbols represent the experimental data and dash lines are calculated with (9).

increases with the pressure. This was due to the increase of the density of supercritical $\mathrm{CO}_{2}$, which led to the increase of the solvent power of the $\mathrm{SC}-\mathrm{CO}_{2}$ [30]. Increasing the temperature increases the diffusivity of the allspice oil through the solid matrix into the fluid; this phenomenon is reflected in the decrease of distribution coefficient. Only at higher pressure and temperature for 5 and $6 \mathrm{~h}$ of contact time did the extraction process have an adequate development $\left(K_{D}>1\right)$, indicating that the concentration of essential oil in the SC$\mathrm{CO}_{2}$ is greater than the remainder concentration.

3.4. Effective Diffusion Coefficient and Energy of Activation. The values of the effective diffusion coefficient at different pressures and temperatures are shown in Table 2. The temperature exhibits a small positive effect on the diffusion

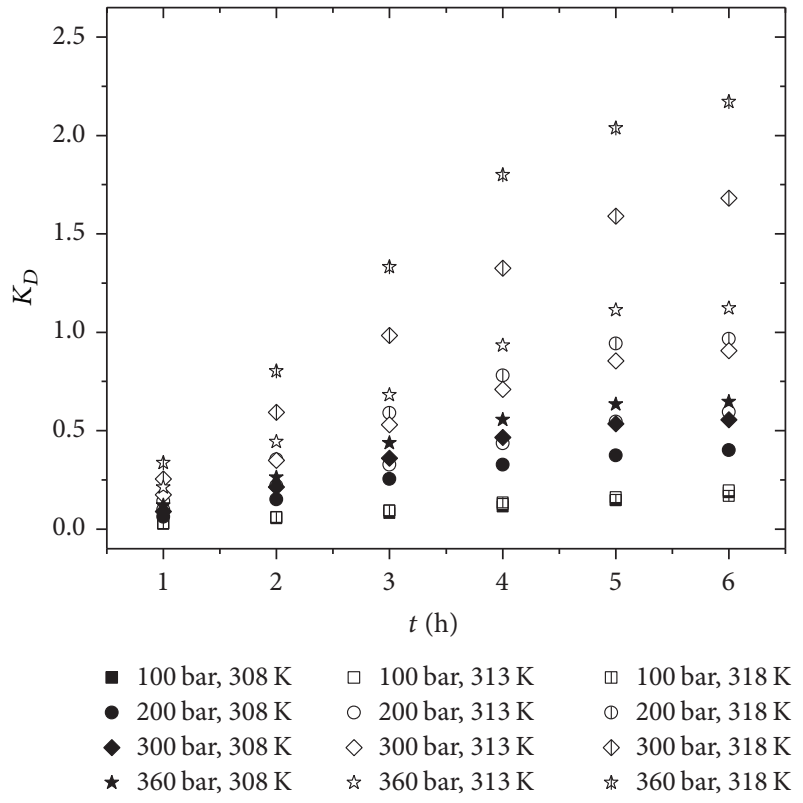

FIGURE 4: Distribution coefficient of allspice essential oil in a supercritical extraction process.

coefficient. The effect caused by an increase of 10 degrees of temperature on diffusion coefficient is twice that achieved with an increase in the pressure of 360 bar. This suggests that to improve the extraction of allspice essential oil would be sufficient to carry out the supercritical extraction at elevated temperatures. However, allspice oil quality obtained at elevated temperatures is inferior, due to loss of volatile compounds.

Small values of the diffusion coefficient are because the main components of allspice oil (eugenol and methyleugenol) are polar compounds. Jin et al. [34] reported that the presence of hydroxyl and carboxyl functional groups renders the extraction more difficult when using only $\mathrm{SC}-\mathrm{CO}_{2}$ as the extracting agent, because the polarity of supercritical carbon dioxide is only comparable with the polarity of pentane. 
TABLE 2: Mean effective diffusion and activation energies.

\begin{tabular}{lcccc}
\hline & 100 bar & 200 bar & 300 bar & 360 bar \\
$T(\mathrm{~K})$ & $10^{-12} D_{\mathrm{ef}}\left(\mathrm{m}^{2} / \mathrm{s}\right)$ & $10^{-12} D_{\mathrm{ef}}\left(\mathrm{m}^{2} / \mathrm{s}\right)$ & $10^{-12} D_{\mathrm{ef}}\left(\mathrm{m}^{2} / \mathrm{s}\right)$ & 2.484 \\
\hline 308.15 & 2.072 & 2.159 & 2.288 & 2.315 \\
313.15 & 2.410 & 2.415 & 2.463 & 2.581 \\
318.15 & 2.416 & 2.480 & 5.976 & 4.397 \\
$E_{a}(\mathrm{~kJ} / \mathrm{mol})$ & 12.594 & 11.328 & 0.858 & 0.945 \\
$r^{2}$ & 0.771 & 0.894 & & \\
\hline
\end{tabular}

TABLE 3: Thermodynamic parameters of the supercritical extraction process.

\begin{tabular}{cccccc}
\hline \multicolumn{4}{c}{$\Delta G^{0}(\mathrm{~J} / \mathrm{mol})$} & $\Delta H^{0}(\mathrm{~J} / \mathrm{mol})$ & $\Delta S^{0}(\mathrm{~J} / \mathrm{mol} \mathrm{K})$ \\
\hline 5h & $1168.15 \mathrm{~K}$ & $313.15 \mathrm{~K}$ & $318.15 \mathrm{~K}$ & & \\
$6 \mathrm{~h}$ & 1117.38 & -277.33 & -1882.48 & -95053.96 & 304.61 \\
\hline
\end{tabular}

The difficulty of the extraction process can also be inferred from the values of the activation energy. The high values of the activation energy of this supercritical extraction are typically characteristic of highly energy-demanding processes.

3.5. Thermodynamic Properties. In Table 3 are shown the results of thermodynamic properties of the supercritical extraction process of allspice essential oil at 5 and $6 \mathrm{~h}$, when the equilibrium was practically reached.

According to the definition of free energy (7), this thermodynamic property can be positive or negative depending on the value of the partition coefficient $\left(K_{D}\right)$. If $K_{D}>0$, the value of the free energy is negative; this means that the amount of extracted oil is greater than the amount of remaining oil and thus the removal process is favorable.

The enthalpy is related to the amount of heat transferred to the extraction process. In this case the process is exothermic and requires removal of a substantial amount of heat. This type of process is favored with increasing temperature.

Positive values of entropy change indicate the irreversibility of the process. At least, for experimental conditions of $300 \mathrm{bar}$ and $318.15 \mathrm{~K}$ and also $360 \mathrm{bar}$ and $313.15 \mathrm{~K}$ and $360 \mathrm{bar}$ and $318.15 \mathrm{~K}$ the supercritical extraction process is spontaneous and irreversible.

3.6. Chromatographic Analysis. The components of the essential oil extracted under supercritical conditions were identified by GC-MS, and the mass fraction of each compound was determined. Figure 5 shows the chromatographic profiles of the extracts obtained with supercritical $\mathrm{CO}_{2}$, in which the presence of eugenol, isoeugenol, methyl eugenol, myrcene, and caryophyllene is found.

Figures 5 and 6 show the chromatograms of the oil obtained by steam distillation (SD) and with supercritical $\mathrm{CO}_{2}$, respectively. A total of 72 compounds are observed in the chromatogram of the oil obtained by SD and 76 compounds in the chromatogram of the oil obtained with

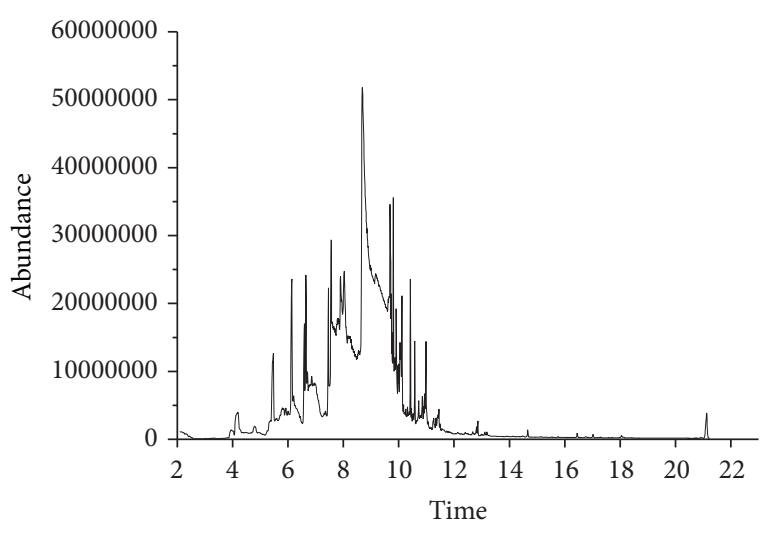

FIgURE 5: Typical chromatogram of essential oil extracted with supercritical $\mathrm{CO}_{2}$.

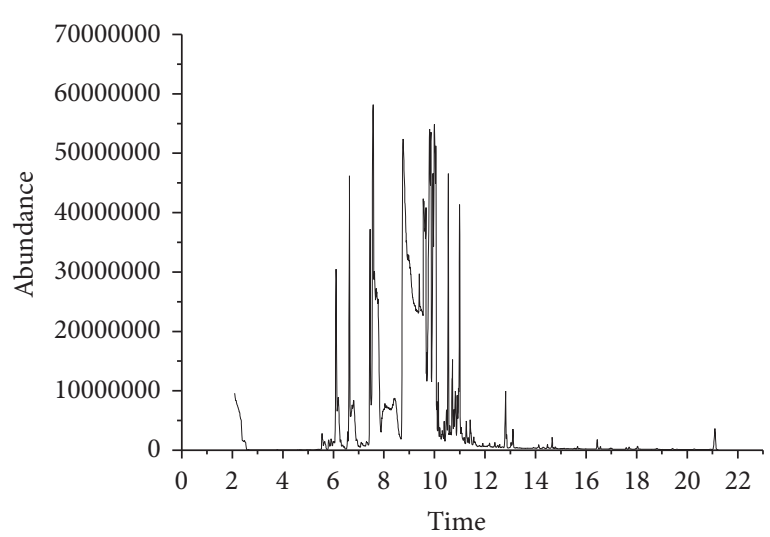

FIGURE 6: Typical chromatogram of essential oil obtained by steam distillation.

supercritical $\mathrm{CO}_{2}$, many of which are in very small concentration. This higher number of compounds obtained by extraction with supercritical carbon dioxide confirms that there are substances that by SD are not extractable. The composition of the essential oils is characterized by having well-defined molecular weight compounds: monoterpenes sesquiterpenes, in addition to other compounds, such as low molecular weight hydrocarbons.

Table 4 shows some of the terpenes extracted by both methods. An interesting fact is the difference between the chromatograms of the oil obtained by SD (Figure 6) and that obtained using supercritical $\mathrm{CO}_{2}$ (Figure 5), in relation to the concentration of monoterpenes, which are not possible 
TABLE 4

\begin{tabular}{cccccc}
\hline & \multicolumn{2}{c}{ Oil obtained by SD } & \multicolumn{3}{c}{ Oil obtained by SC-CO ${ }_{2}$} \\
& $\%$ & Compounds & & $\%$ & Compounds \\
\hline 1 & 27.34 & Eugenol & 1 & 34.44 & Eugenol \\
2 & 0.33 & Myrcene & 2 & 0.54 & Myrcene \\
3 & 9.73 & Caryophyllene & 3 & 1.64 & Caryophyllene \\
4 & 0.37 & Methyl eugenol & 4 & 2.54 & Methyl eugenol \\
\hline
\end{tabular}

to obtain by $\mathrm{SD}$, since the use of high temperatures does not allow its efficient extraction. These differences in composition of terpenes affect the physicochemical properties of the oil: the oil richer in sesquiterpenes will be more stable at temperature and more polar and will have higher boiling point, while the oil richer in monoterpenes will be more volatile and less polar and will have lower boiling point.

\section{Conclusions}

The extraction process for allspice essential oil with supercritical $\mathrm{CO}_{2}$ is a temperature and pressure dependent operation. The maximum extraction yield reached was of $68.47 \%$ at $318.15 \mathrm{~K}, 360 \mathrm{bar}$, and $6 \mathrm{~h}$ of contact time. The higher experimental apparent solubility values obtained between 100 and 360 bar and reported in mass fraction ranged from $1.385 \cdot 10^{-6}$ to $1.948 \cdot 10^{-6}, 1.893 \cdot 10^{-6}$ to $2.674 \cdot 10^{-6}$, and $2.605 \cdot 10^{-6}$ to $3.666 \cdot 10^{-6}$ at $308.15,313.15$, and $318.15 \mathrm{~K}$, respectively. The experimental apparent solubility data were successfully correlated with the modified Chrastil equation. The values of the thermodynamics properties $\Delta G^{0}<0, \Delta H^{0}>0$, and $\Delta S^{0}>0$ indicate that the supercritical extraction process of allspice oil is spontaneous, exothermic, and irreversible. The values of the effective diffusion coefficient as function of temperature and pressure are between $1.95 \cdot 10^{-10}$ and 2.11 . $10^{-9} \mathrm{~m}^{2} / \mathrm{h}$; the energy of activation [107.96-123.70 kJ/mol] and the distribution coefficient [0.03-2.17] suggest that this is a difficult operation and high energy-demanding process. The essential oil extracted with supercritical $\mathrm{CO}_{2}$ was analyzed with GC-MS, finding differences in the composition with the oil extracted by steam drag, finding that in the extraction with supercritical carbon dioxide a greater amount of compounds is obtained that they present a greater molecular weight. Therefore, supercritical extraction is considered as an optimum process for obtaining allspice oil with high quality.

\section{Additional Points}

Highlights. (i) The higher extraction yield reached was of $68.47 \%$ at $318.15 \mathrm{~K}, 360 \mathrm{bar}$, and $6 \mathrm{~h}$ of contact time. (ii) The experimental apparent solubility data were successfully correlated with the modified Chrastil equation. (iii) The values of the thermodynamics properties $\left(\Delta G^{0}<0, \Delta H^{0}>0\right.$, and $\Delta S^{0}>0$ ) indicate that the supercritical extraction process of allspice oil is spontaneous, exothermic, and irreversible.

\section{Conflicts of Interest}

The authors declare that they have no conflicts of interest.

\section{Acknowledgments}

The authors acknowledge the financial support from CONACYT. Yasvet Y. Andrade-Avila is grateful to CONACYT for Scholarship no. 701366 to conduct postgraduate studies.

\section{References}

[1] B. Krishnamoorthy and J. Rema, "Allspice," Handbook of Herbs and Spices, vol. 2, pp. 117-139, 2004.

[2] B. Marongiu, A. Piras, S. Porcedda, R. Casu, and P. Pierucci, "Comparative analysis of supercritical $\mathrm{CO} 2$ extract and oil of Pimenta dioica Leaves," Journal of Essential Oil Research, vol. 17, no. 5, pp. 530-532, 2005.

[3] F. A. Draughon, "Use of botanicals as biopreservatives in foods," Food Technology, vol. 58, no. 2, pp. 20-27, 2004.

[4] E. Schmidt, L. Jirovetz, K. Wlcek et al., "Antifungal activity of eugenol and various eugenol-containing essential oils against 38 clinical isolates of candida albicans," Journal of Essential Oil Bearing Plants, vol. 10, no. 5, pp. 421-429, 2007.

[5] M. Zabka, R. Pavela, and L. Slezakova, "Antifungal effect of Pimenta dioica essential oil against dangerous pathogenic and toxinogenic fungi," Industrial Crops and Products, vol. 30, no. 2, pp. 250-253, 2009.

[6] M. Martinez-Velazquez, G. A. Castillo-Herrera, R. RosarioCruz et al., "Acaricidal effect and chemical composition of essential oils extracted from Cuminum cyminum, Pimenta dioica and Ocimum basilicum against the cattle tick Rhipicephalus (Boophilus) microplus (Acari: Ixodidae)," Parasitology Research, vol. 108, no. 2, pp. 481-487, 2011.

[7] K. P. P. Amma, M. P. Rani, I. Sasidharan, and M. M. Sreekumar, "Comparative chemical composition and in vitro antioxidant activities of essential oil isolated from the leaves of Cinnamomum tamala and Pimenta dioica," Natural Product Research, vol. 27, no. 3, pp. 290-294, 2013.

[8] C. Dima, M. Cotârlet, P. Alexe, and S. Dima, "Microencapsulation of essential oil of pimento [Pimenta dioica (L) Merr.] by chitosan/k-carrageenan complex coacervation method," Innovative Food Science \& Emerging Technologies, vol. 22, pp. 203211, 2014.

[9] E. O. Sánchez-Sáenz, C. Pérez-Alonso, J. Cruz-Olivares, A. Román-Guerrero, J. G. Baéz-González, and M. E. RodríguezHuezo, "Establishing the most suitable storage conditions for microencapsulated allspice essential oil entrapped in blended biopolymers matrices," Drying Technology, vol. 29, no. 8, pp. 863-872, 2011.

[10] O. S. Monteiro, A. G. Souza, L. E. B. Soledade et al., "Chemical evaluation and thermal analysis of the essential oil from the fruits of the vegetable species Pimenta dioica Lindl," Journal of Thermal Analysis and Calorimetry, vol. 106, no. 2, pp. 595-600, 2011.

[11] J. Briozzo, L. Núñez, J. Chirife, L. Herszage, and M. D’Aquino, "Antimicrobial activity of clove oil dispersed in a concentrated sugar solution," Journal of Applied Bacteriology, vol. 66, no. 1, pp. 69-75, 1989.

[12] K. P. Padmakumari, I. Sasidharan, and M. M. Sreekumar, "Composition and antioxidant activity of essential oil of pimento (Pimenta dioica (L) Merr.) from Jamaica," Natural Product Research, vol. 25, no. 2, pp. 152-160, 2011.

[13] H. Kikuzaki, S. Hara, Y. Kawai, and N. Nakatani, "Antioxidative phenylpropanoids from berries of Pimenta dioica," Phytochemistry, vol. 52, no. 7, pp. 1307-1312, 1999. 
[14] Y. Nitta, H. Kikuzaki, and H. Ueno, "Inhibitory activity of Pimenta dioica extracts and constituents on recombinant human histidine decarboxylase," Food Chemistry, vol. 113, no. 2, pp. 445-449, 2009.

[15] M. Mueller, S. Hobiger, and A. Jungbauer, "Anti-inflammatory activity of extracts from fruits, herbs and spices," Food Chemistry, vol. 122, no. 4, pp. 987-996, 2010.

[16] N. Shamaladevi, D. A. Lyn, K. A. Shaaban et al., "Ericifolin: A novel antitumor compound from allspice that silences androgen receptor in prostate cancer," Carcinogenesis, vol. 34, no. 8, pp. 1822-1832, 2013.

[17] A. R. Geetha, E. George, A. Srinivasan, and J. Shaik, "Optimization of green synthesis of silver nanoparticles from leaf of Pimenta dioica (Allspice)," The Sciemtific World Journal, vol. 2013, Article ID 362890, 5 pages, 2013.

[18] A. Piras, A. Rosa, D. Falconieri, S. Porcedda, M. A. Dessì, and B. Marongiu, "Extraction of oil from wheat germ by supercritical CO2," Molecules, vol. 14, no. 7, pp. 2573-2581, 2009.

[19] G. Brunner, "Supercritical fluids: Technology and application to food processing," Journal of Food Engineering, vol. 67, no. 1-2, pp. 21-33, 2005.

[20] J. García-Fajardo, M. Martínez-Sosa, M. Estarrón-Espinosa, G. Vilarem, A. Gaset, and J. M. De Santos, "Comparative Study of the Oil and Supercritical CO2 Extract of Mexican Pimento (Pimenta dioica Merrill)," Journal of Essential Oil Research, vol. 9, no. 2, pp. 181-185, 1997.

[21] A. Kubátová, B. Jansen, J.-F. Vaudoisot, and S. B. Hawthorne, "Thermodynamic and kinetic models for the extraction of essential oil from savory and polycyclic aromatic hydrocarbons from soil with hot (subcritical) water and supercritical CO2," Journal of Chromatography A, vol. 975, no. 1, pp. 175-188, 2002.

[22] S. Machmudah, M. Kondo, M. Sasaki, M. Goto, J. Munemasa, and M. Yamagata, "Pressure effect in supercritical CO2 extraction of plant seeds," Journal of Supercritical Fluids, vol. 44, no. 3 , pp. 301-307, 2008.

[23] J. Cruz-Olivares, C. H. Ortiz-Estrada, C. Pérez-Alonso, M. C. Chaparro-Mercado, and C. Barrera-Díaz, "Solubility of mesquite gum in supercritical carbon dioxide," Journal of Chemical and Engineering Data, vol. 56, no. 5, pp. 2449-2452, 2011.

[24] H. S. Ghaziaskar and M. Kaboudvand, "Solubility of trioctylamine in supercritical carbon dioxide," Journal of Supercritical Fluids, vol. 44, no. 2, pp. 148-154, 2008.

[25] Z. Huang, Y. C. Chiew, W.-D. Lu, and S. Kawi, "Solubility of aspirin in supercritical carbon dioxide/alcohol mixtures," Fluid Phase Equilibria, vol. 237, no. 1-2, pp. 9-15, 2005.

[26] C. Pérez-Alonso, J. Cruz-Olivares, A. Ramírez, A. RománGuerrero, and E. J. Vernon-Carter, "Moisture diffusion in allspice (Pimenta dioica L. Merril) fruits during fluidized bed drying," Journal of Food Processing and Preservation, vol. 35, no. 3, pp. 308-312, 2011.

[27] J. Chrastil, "Solubility of solids and liquids in supercritical gases," Journal of Physical Chemistry, vol. 86, no. 15, pp. 30163021, 1982.

[28] Y. Sun and S. Li, "Measurement and correlation of the solubility of Ligusticum Chuanxiong oil in supercritical $\mathrm{CO}_{2}$," Chinese Journal of Chemical Engineering, vol. 13, no. 6, pp. 796-799, 2005.

[29] G. S. V. Raghavan, T. N. Tulasidas, S. S. Sablani, and H. S. Ramaswamy, "A method of determination of concentration dependent effective moisture diffusivity," Drying Technology, vol. 13, no. 5-7, pp. 1477-1488, 1995.
[30] J. Shim and R. Gupta, Solubility in Supercritical Carbon Dioxide, CRC Press, Boca Raton, Fla, USA, 2006.

[31] J. Min, S. Li, J. Hao, and N. Liu, "Supercritical CO2 extraction of jatropha oil and solubility correlation," Journal of Chemical and Engineering Data, vol. 55, no. 9, pp. 3755-3758, 2010.

[32] V. Louli, G. Folas, E. Voutsas, and K. Magoulas, "Extraction of parsley seed oil by supercritical $\mathrm{CO}_{2}$," Journal of Supercritical Fluids, vol. 30, no. 2, pp. 163-174, 2004.

[33] E. Z. Chimowitz, Introduction to Critical Phenomena in Fluids, Oxford University Press, Oxford, UK, 2005.

[34] J.-S. Jin, X. Fan, H. Zhang, Y.-W. Wang, and Z.-T. Zhang, "Solubility of 4-aminosalicylic acid in supercritical carbon dioxide and subcritical 1,1,1,2-tetrafluoroethane," Journal of Chemical and Engineering Data, vol. 59, no. 6, pp. 2095-2100, 2014. 

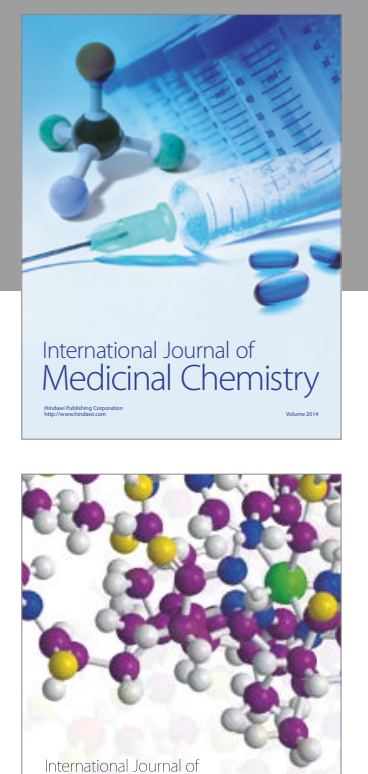

Carbohydrate Chemistry

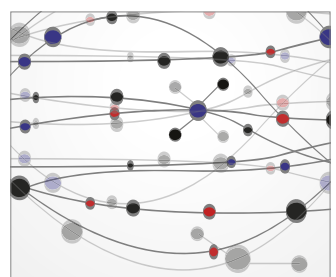

The Scientific World Journal
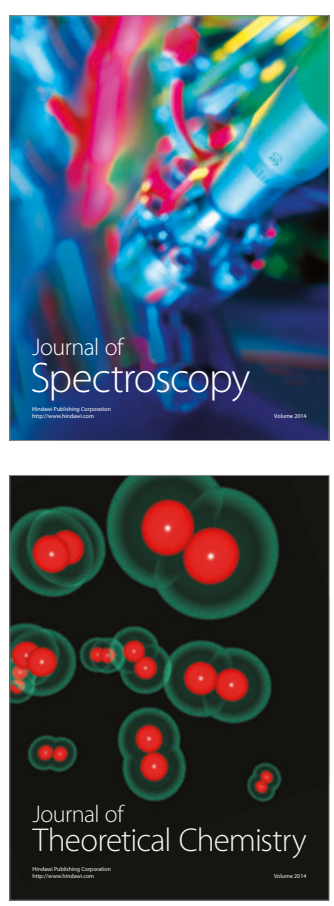
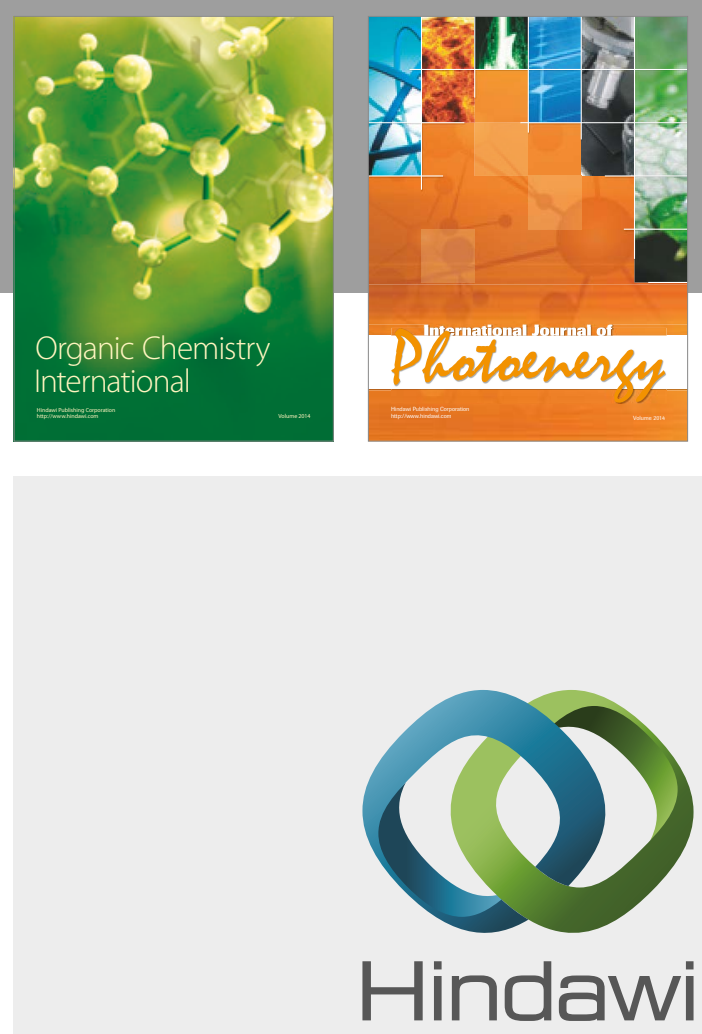

Submit your manuscripts at

https://www.hindawi.com

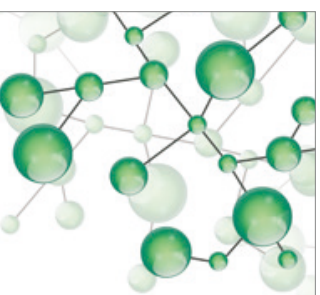

International Journal of

Inorganic Chemistry

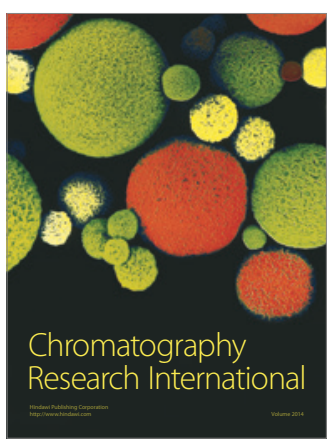

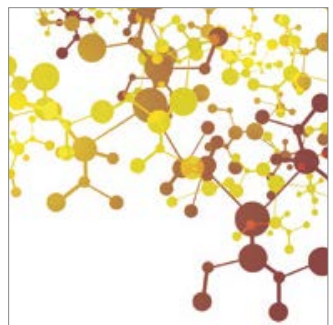

Applied Chemistry
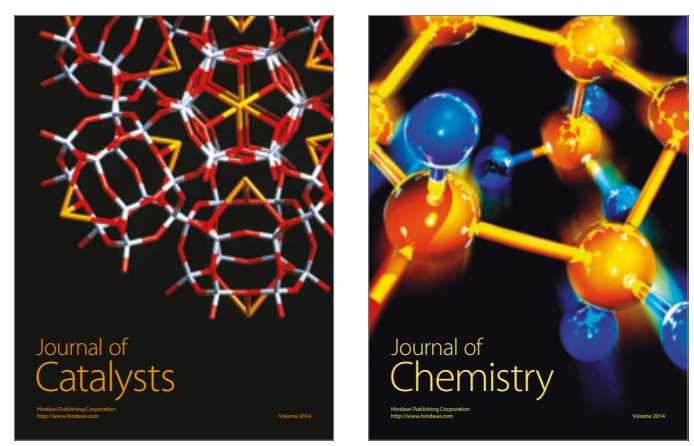
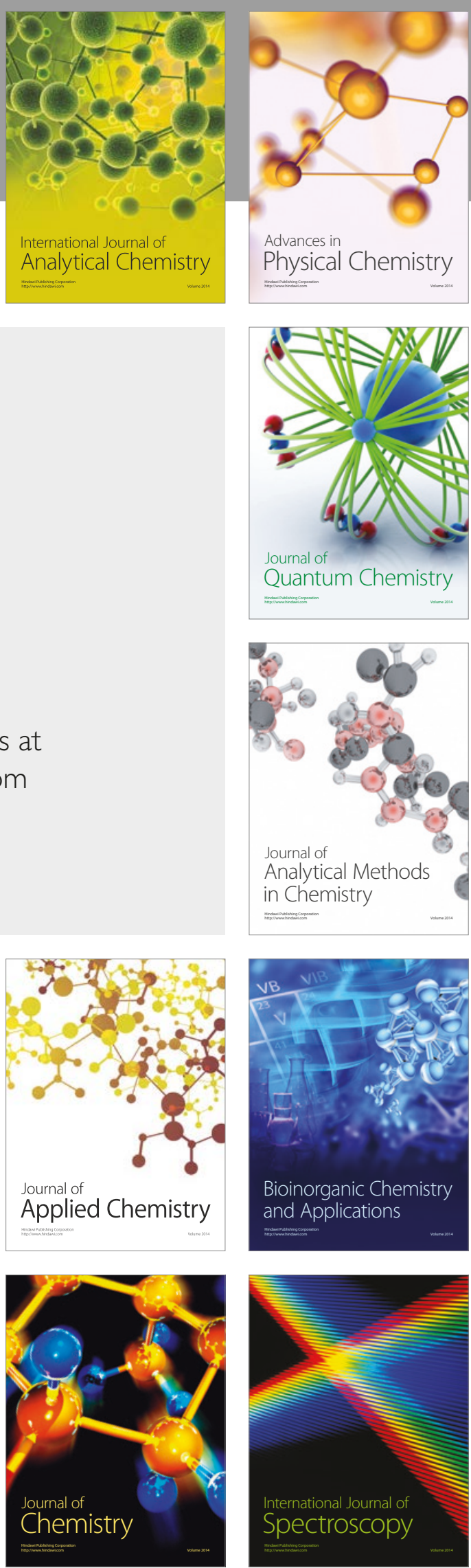